\title{
LEACH-S2: A Brief Approach on a Proposal of an Energy Efficient LEACH Routing
}

\author{
Md. Faruk Abdullah Al Sohan \\ Department of Computer Science, American International University-Bangladesh, Dhaka \\ Email: farukabdullahh@gmail.com \\ Afroza Nahar \\ Department of Computer Science, American International University-Bangladesh, Dhaka \\ Email: afroza@aiub.edu \\ Md Sajid Bin-Faisal \\ Department of Computer Science, American International University-Bangladesh, Dhaka \\ Email: sajid @aiub.edu
}

\begin{abstract}
Wireless Network consists of several sensors and data communication among them in a cluster basis. This report focusses on the comparison and description of several Low Energy Adaptive Clustering Hierarchy (LEACH) routing protocol with the reason of their energy efficient routing activity. In wireless network implemented with sensors, it is required to develop an energy efficient routing protocol for making the lifetime of the network longer. The comparison of these protocols with the base LEACH and then identifying the advantage and some issues regarding energy efficiency is the core concern of this work. After comparison and description of the LEACH protocols, a new approach is proposed along with the workflow of its routing activity and cluster head formation to make a more energy efficient LEACH approach in the future days.
\end{abstract}

Keywords - Clustering, cluster head, communication, energy-efficient, LEACH (Low Energy Adaptive Clustering Hierarchy).

Date of Acceptance: Oct 05, 2021

\section{INTRODUCTION}

The modern world of technology depends much on the Wireless Sensor based networks. The global trade and ecommerce sites all have now started focusing over the communication through Wireless channels. So, the need and hunger for dependable and less failure prone Wireless communication have increased day by day. The future world of $5 \mathrm{G}$ communication and technologies will be dependent to Wireless networks. The unlimited data transmission and massive amount of packet passage are expected to be fulfilled in a well-constructed Wireless communication. The architecture and the routing protocol of the network must be efficient and less delay prone in terms of service and management of the entire system. So, for enabling a reliable and fast communication technique to serve the requirement of the future services, efficient routing protocol is a must. Yet, that needs to be cost effective and reasonably less energy consuming.

Wireless Networks are basically constructed with the deployment of several sensor nodes in a network design. The nodes are typically sensors and other small processors of limited computational capacity are used in the network thus, it is called the Wireless Sensor Networks (WSN). The sensors take the information from outside interface for further processing and computation before propagation in the deeper channels of the network. These sensors can be a temperature sensor, sometimes a sound sensor, humidity detecting sensor, weight measurement sensor, soil moisturizer sensor, light intensity sensor and many more.
The sensor networks generally connected to a Base station and several clusters deployed in it [1].

The Base stations are the main information processors and the core of the network architecture. There can be either one or more than one Base stations in a network. The clusters are consisting of several similar and related working procedure-based sensors. There can be a source node in which the data is propagated to the Cluster Head (CH) of each cluster. These $\mathrm{CHs}$ are the general intermediaries in-between the sensors and the Base station.

A service depends much on the successful propagation and transmission of data in the network system. Hence, an efficient routing protocol is required to manage the directories and hierarchy of the network. Also, it can determine the access mechanism and communication description for the specific architecture of the network. It should be managed within the budget and manageable capabilities regarding power / energy in the deployed system. It should not exceed its manageability and tolerance level for an extravagant routing protocol. If the management of the routing protocol is efficiently handled, the work can get easier, and it would be also providing the Quality of Service (QoS). Also, the sensor in the system has limited life period therefore energy consumption and efficiency in energy usage should be the matters of concern in WSN. The reliable propagation of the massage among the network layers from the nodes is the basic working principle of wireless network. In this consequence, the necessity of a reliable and energy 
efficient routing protocol is needed [2]. The conservation of energy in transmission of a communication network along with excessive occurrences avoidance is a general task to ensure [3].

The Vehicle oriented adhoc network performance is highly changed through the fading impact like NakaGami Channel. Routing protocols like link state routing can preserve the performance efficiency of the VANET system considering the fading effect of the channel [4]. Sensor networks depend over the routing protocols, computational mechanisms, power supply and life span of the sensor nodes. These sensors need to be designed in such a cluster that the WSN nodes get the equal distribution of power and activity. The solution to this problem can be solved with the different approach of unequal clustering. Because power supply and life span of the sensor nodes rely over the clustering manner and structure [5].

Among the routing protocols available, Low Energy Adaptive Clustering Hierarchy which is a cluster orientation-based routing protocol named as LEACH has several forms. These will be discussed one by one. Comparatively, these are the routing protocols which concerns about the energy efficiency of the nodes and system environment mostly.

In this paper, an energy efficient LEACH routing protocol is going to be demonstrated analyzing the pros and cons of several renowned LEACH protocols in the industry usage. The standardization of that specific protocol would be based on the studies over the other existing protocols by far. The contribution of this report is to come up with the idea and general visualization of an acceptable LEACH protocol.

\section{LITERATURE REVIEW}

\subsection{TL-LEACH (Two-Level LEACH)}

Though a LEACH protocol is energy efficient, there may arise some problems during sending aggregation data which are collected from the cluster nodes of the network. Generally, in a network the cluster notes collect data and send to the Cluster Head $(\mathrm{CH})$ and then $\mathrm{CH}$ sends the data in the Base Station (BS). But in a networked design, most of the $\mathrm{CH}$ are located so far from the BS. As a result, the energy consumption of a $\mathrm{CH}$ is become high during transmitting the data and for this reason, the $\mathrm{CH}$ might die earlier than the others and lost all the data which are stored in the CHs. To overcome this problem, a new LEACH protocol is proposed in [6] name Two-Level LEACH (TLLEACH).

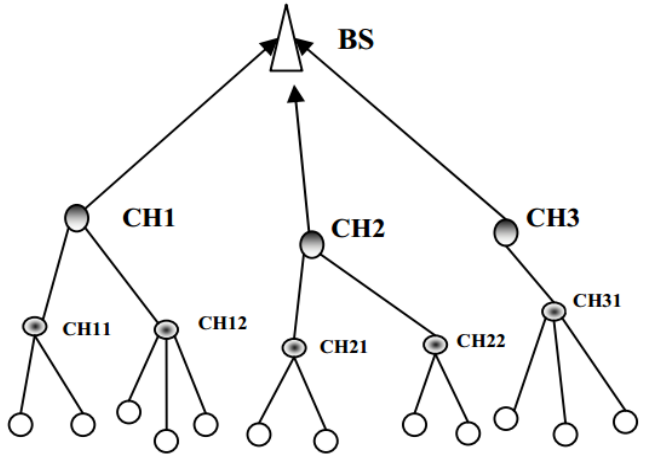

Fig.1. TL-LEACH Protocol [7]

In this protocol, $\mathrm{CHs}$ are in two layers. The distance between the $\mathrm{BS}$ and $\mathrm{CH}$ has reduced. It also follows the original LEACH protocol but in a sophisticated way. In this protocol, cluster nodes send data to the nearest $\mathrm{CHs}$, then the $\mathrm{CHs}$ send the data to the upper layer $\mathrm{CHs}$ and finally the upper layer CHs send the data to the BS directly within a very short time with a very low power consumption $[7,12]$. It can transmit more data because of having low latency [6]. It has also a drawback. In this protocol, there is no centralized control. As result, the BS cannot control the sensor nodes [11].

\subsection{V-LEACH (Vice-Cluster Head LEACH)}

In the basic LEACH protocol, Cluster Heads (CHs) are selected randomly. It does not check whether the node is able to poise the network or not. As a result, most of the time many parts of the network may damage and make the network unreliable. Further, there may occur a situation which is responsible for data lost and it arises during transmitting data from a $\mathrm{CH}$ to a Base Station (BS). It is the main deficiency of this protocol. To make the network reliable by fixing these problems, a new LEACH protocol is introduced named Vice-Cluster Head LEACH. In this protocol, a new type of $\mathrm{CH}$ is introduced named vice- $\mathrm{CH}$. Those who have higher energy and lower distance from the $\mathrm{BS}$ are selected for $\mathrm{CH}$ and vice- $\mathrm{CH}$. Generally, $\mathrm{CH}$ is responsible for sending the collected data to the $\mathrm{BS}$.

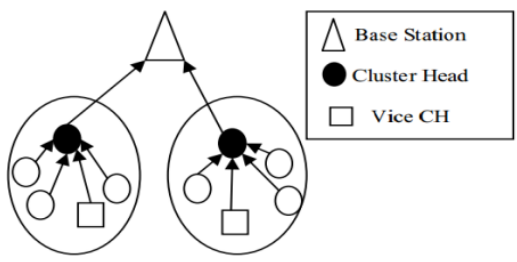

Fig. 2. V-LEACH Protocol [7]

If somehow it dies, then the vice- $\mathrm{CH}$ will automatically become the $\mathrm{CH}$ of this network. As a result, this part of the network may not down. It helps to increase the lifetime of a network [11]. But if the vice-CH dies, the whole network will die very quickly as the energy fritters away completely within a very short time [7]. Though it has 
some disadvantages, it performs better than the others [10].

\subsection{M-LEACH (Multi-Hop LEACH)}

LEACH protocol uses single hop communication for transmitting data from Cluster Head $(\mathrm{CH})$ to the Base Station (BS). When the distance between $\mathrm{BH}$ and $\mathrm{CH}$ increases, the overall performance of the network will be lower than the before. As it consumes more energy for transmitting the received data. When any $\mathrm{CH}$ cannot manage enough energy, it may die, and the network becomes unbalanced. To increase the overall performance by reducing the energy consumption, a new LEACH is proposed which is known as Multi-Hop LEACH (MLEACH).

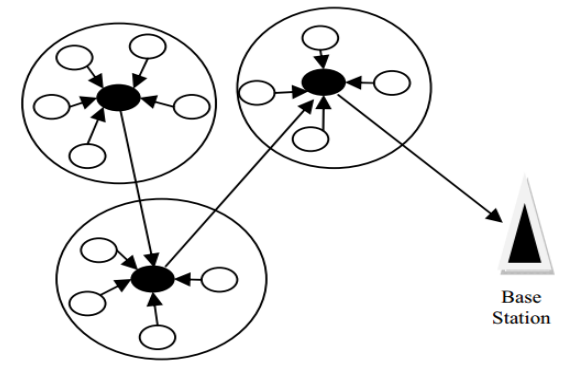

Fig. 3. M-LEACH Protocol [7]

In this protocol it uses multiple hops. The benefit of having multiple hops is that it does not need to transmit data directly to the BS using the long distance. $\mathrm{CHs}$ are responsible for data co-ordination and then the fusion data are sent to the BS. As it does not use long distance for communication, so it can save a huge amount of energy. It follows complete distributed clustering routing protocol [7]. Though it provides low power consumption communication, it takes more time for communication.

\subsection{LEACH-S (Solar-Aware LEACH)}

Solar LEACH is the routing protocol which is powered by the sun or solar energy. Here the energy is transmitted from the source of Sun. The energy nodes which have higher energy level are defined as the cluster head of each cluster. In terms of Cost and other energy constrained limitations this routing protocol is useful. As the sun is the source of energy, the power does not come from the other sort of energy sources. It can be constructed by following 2 different types of models. One is the Centralized Solar LEACH and the other is the Distributed Solar LEACH [7]. When it is difficult to reach and control the nodes in a network the most useful activity is to construct the Solar Aware LEACH protocol in it.

The Centralized model of the LEACH-S has been designed in such a way that it allocates the $\mathrm{CH}$ according to the level of unused energy in the node. The higher the unconsumed energy of the node, the higher the chance of its being the $\mathrm{CH}$ by the Base Station. If in case the energy level goes down for the $\mathrm{CH}$, a new $\mathrm{CH}$ with higher energy level unused is assigned. So, the transfer of the $\mathrm{CH}$ duty can be split if needed for the network and to keep the network activity running.
The distributed LEACH-S is quite different from the centralized model. Here more privilege is given to the nodes run by the solar energy. There are also nodes which are run by the battery sources. The selection criteria of the Cluster Head are made by the decision of the solar powered nodes in the cluster. One of them becomes the $\mathrm{CH}$ and communicates with the Base station on behalf of the nodes in the cluster.

It is an environment friendly and energy efficient routing protocol in WSN. As the solar energy is the main power source, cost is lesser in terms of compassion with another LEACH protocol. It is very useful for the countries which have longer daytime and thus it may lead to a prolonged life of the sensors and the network. Shorter day duration such as some European countries like Iceland, Norway, Sweden is not efficient for using this routing protocol.

\subsection{T-LEACH (Threshold-Based LEACH)}

Threshold Based LEACH is a protocol Where there are three stages of its operation. The first one is the message passing phase. In this stage the Cluster Heads gives a message to the other nodes about its power information. It also passes the message which indicates and lets the other nodes in the cluster to know about the times of iteration it worked as Cluster Head. Then it starts to form a cluster with the number of adjacent neighbor nodes in the network. Distance is a very important issue in energy efficiency in this protocol. The distance may cover the amount of energy consumed from one node to another in the time of propagation. There is a limited amount of energy consumption defined in this protocol for the distance coverage from one node to another.

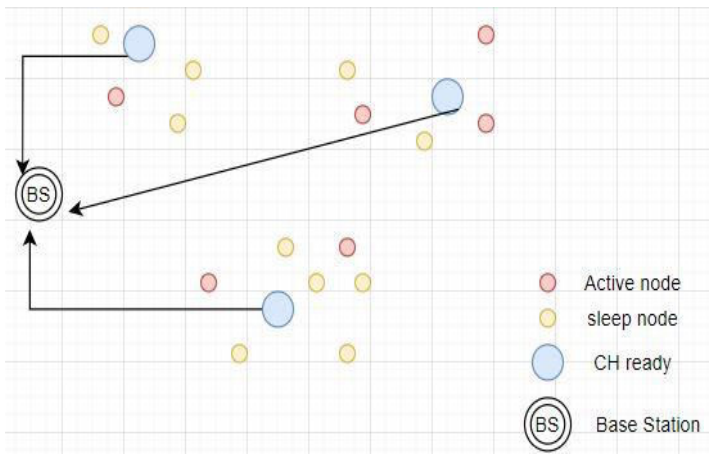

Fig.4 Cluster formation by T-LEACH in network [8]

The propagation for the minimal distance coverage to limit the energy consumption has been classified in two different models named as two Ray model and Free space propagation. These minimal coverage limit defined for each model helps to reduce the energy consumption of nodes for this protocol. It has been seen that the life expectancy of the T-LEACH protocol is higher than the conventional LEACH protocol.

The number of rounds accomplished in the T-LEACH protocol-based network is relatively higher compared to the rounds accomplished in the LEACH protocol base network. There can be about 7100 rounds can be found accomplished successfully in T-LEACH, but it is not more than 6600 rounds in Basic LEACH based network [8]. 
Also, the amounts of successful packet passage in each round are higher in T-LEACH comparatively.

\subsection{R-LEACH}

This protocol is based on RFID technology. The model is designed Energy efficiently and limited to energy consumption. There are several node type and propagation criteria in this routing protocol.

There are cluster heads, sensor nodes which can be either active or in sleep mode. The active and sleep mode is used here for reducing the energy consumption of the node and limit the waste of energy of the nodes in the network. The most important part of this protocol is that it is designed in such a way that the nodes does not require a lot of power to construct, and they are basically run with Radio Frequency Identification tag system. The cluster heads of each cluster are in ready state to transmit the data taken from the other nodes of that cluster [9]. The visual representation of the R-LEACH is shown below:

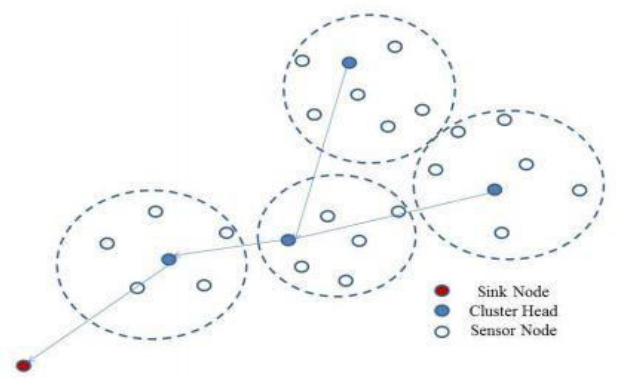

Fig.5 R-LEACH protocol with active, sleep node in the cluster

In comparison with the existing LEACH protocol the RLEACH routing protocol is less delay prone in terms of packet passage. Also, the performance throughput of RLEACH is way better than LEACH protocol. The computational power overhead incurred in $\mathrm{LEACH}$ is higher than the R-LEACH as it uses the RFID based information storage and propagation. The sleep and activeduty cycle along with the ready state of the $\mathrm{CH}$ in the clusters are responsible for making this protocol more energy efficient than normal LEACH. The energy level of the $\mathrm{CH}$ is saved for the sleep mode duration of several nodes in the cluster and thus uses less energy to transmit data to the Base Station.

\section{ADVANTAGE AND DRAWBACKS OF THE EXISTING LEACH PROTOCOLS}

The drawbacks and the advantages observed in terms of energy efficiency are demonstrated in the table below. This table basically focusses on why the LEACH routing protocols are considered energy efficient and what causes their problems to handle energy efficiency. Most of them have been seen that $\mathrm{CH}$ formation, energy source, distance coverage and phases of activity is the basic concerns to analyze.
Table 1: Advantages and drawbacks of LEACH routing protocols in terms of energy efficiency.

\begin{tabular}{|c|c|c|}
\hline $\begin{array}{l}\text { Routing } \\
\text { Protocol }\end{array}$ & $\begin{array}{l}\text { Advantage in } \\
\text { terms of energy } \\
\text { efficiency }\end{array}$ & Drawback \\
\hline $\begin{array}{c}\text { TL- } \\
\text { LEACH }\end{array}$ & $\begin{array}{l}\text { Two level cluster } \\
\text { head formation for } \\
\text { saving the energy. } \\
\text { As energy is } \\
\text { consumed for } \\
\text { propagating a } \\
\text { higher distance if } \\
\text { there is no medium } \\
\text { level for } \mathrm{CH} \text {. }\end{array}$ & $\begin{array}{l}\text { No centralized } \\
\text { control of the Base } \\
\text { station. So, there is } \\
\text { a chance to be error } \\
\text { prone propagation } \\
\text { that can lead to an } \\
\text { energy wastage. No } \\
\text { better centralized } \\
\text { control that is } \\
\text { energy efficient for } \\
\text { the cluster nodes. }\end{array}$ \\
\hline V-LEACH & $\begin{array}{l}\text { Vice Cluster Head } \\
\text { for saving the } \\
\text { whole network } \\
\text { cluster in case of } \\
\text { CH failure / death. } \\
\text { Also, it gives a } \\
\text { backup for the } \\
\text { cluster if needed. }\end{array}$ & $\begin{array}{l}\text { The failure of the } \\
\text { vice Cluster head } \\
\text { may lead to the } \\
\text { whole network } \\
\text { communication } \\
\text { failure. Thus, a } \\
\text { huge number of } \\
\text { energies may be } \\
\text { wasted if the } \\
\text { sensors with } \\
\text { highest energy } \\
\text { level dies together. }\end{array}$ \\
\hline M-LEACH & $\begin{array}{l}\text { Multi-hop } \\
\text { communication } \\
\text { technique can } \\
\text { reduce the amount } \\
\text { of energy loss for a } \\
\text { certain amount of } \\
\text { distance coverage } \\
\text { through } \\
\text { intermediate points } \\
\text { of network. It can } \\
\text { save energy } \\
\text { compared to the } \\
\text { direct hoping } \\
\text { technique. Also, the } \\
\text { energy of a single } \\
\text { node is saved } \\
\text { significantly. }\end{array}$ & $\begin{array}{l}\text { Sometimes, multi- } \\
\text { hoping technique it } \\
\text { takes a massive } \\
\text { amount of time for } \\
\text { a certain distance } \\
\text { coverage. So, } \\
\text { generally it can } \\
\text { cause delay in a } \\
\text { network leading to } \\
\text { inefficiency energy } \\
\text { usage. }\end{array}$ \\
\hline T-LEACH & $\begin{array}{l}\text { A threshold value } \\
\text { used in the } \mathrm{CH} \\
\text { formation and work } \\
\text { in the protocol is } \\
\text { defined. Minimal } \\
\text { distance assigned } \\
\text { for the coverage of } \\
\text { Free space and } 2 \\
\text { ray model } \\
\text { propagation gives } \\
\text { the threshold } \\
\text { distance value a } \\
\text { chance to limit the } \\
\text { energy } \\
\text { consumption and }\end{array}$ & $\begin{array}{l}3 \text { different phase of } \\
\text { message passing \& } \\
\text { broadcasting, } \\
\text { listing } \\
\text { propagation } \\
\text { management may } \\
\text { not always be } \\
\text { energy efficient for } \\
\text { the small sensor } \\
\text { processors. }\end{array}$ \\
\hline
\end{tabular}




\begin{tabular}{|c|c|c|}
\hline & $\begin{array}{l}\text { ensures the energy } \\
\text { usage as per the } \\
\text { requirement. }\end{array}$ & \\
\hline R-LEACH & $\begin{array}{l}\text { Radio Frequency } \\
\text { based (RFID) } \\
\text { nodes in the cluster } \\
\text { are used for } \\
\text { minimal } \\
\text { computational and } \\
\text { power can } \\
\text { overhead that can } \\
\text { be considered as an } \\
\text { energy efficient } \\
\text { approach of } \\
\text { routing. Active- } \\
\text { sleep modes of the } \\
\text { nodes are here that } \\
\text { can save a good } \\
\text { amount of energy } \\
\text { for being wasted if } \\
\text { the nodes are } \\
\text { efficiently switched } \\
\text { to sleep mode from } \\
\text { active mode when } \\
\text { it does not have } \\
\text { anything to do but } \\
\text { rest. }\end{array}$ & $\begin{array}{l}\text { Sometimes the } \\
\text { active-sleep cycle } \\
\text { is not efficiently } \\
\text { and adaptively } \\
\text { handled. So, there } \\
\text { is a chance of a } \\
\text { node still being } \\
\text { active even if is not } \\
\text { about to work or } \\
\text { perform its duty in } \\
\text { a certain period. } \\
\text { Hence, for that } \\
\text { period of time } \\
\text { energy is wasted } \\
\text { and loss of energy } \\
\text { is observed. }\end{array}$ \\
\hline LEACH-S & $\begin{array}{l}\text { Solar energy source } \\
\text { is used. The } \\
\text { amount of } \\
\text { unconsumed or } \\
\text { unused energy of } \\
\text { the nodes can be } \\
\text { detected as CH } \\
\text { according to the } \\
\text { privilege set. Better } \\
\text { energy backup } \\
\text { compared to the } \\
\text { battery powered } \\
\text { nodes. }\end{array}$ & $\begin{array}{l}\text { If the availability of } \\
\text { sun is about a less } \\
\text { than a minimal } \\
\text { duration of the day, } \\
\text { the system lacks in } \\
\text { energy source for } \\
\text { network data } \\
\text { communication and } \\
\text { propagation task. }\end{array}$ \\
\hline
\end{tabular}

\section{Proposed MOdeL}

The existing energy efficient models are used in the industries to reduce the energy consumption and to have a successful communication of wireless network. All of the protocols are well accepted in the global scenarios of network. Yet, each of these protocols are found to have some problems or drawbacks that can be enhanced towards a better energy efficient approach of wireless network routing. So, there is a proposed model that is enhanced from the recent protocols of $\mathrm{LEACH}$ and discussed it working procedure and the way it makes the reduction of energy consumption in the cluster based wireless network platform.

There in this literature, six different LEACH routing protocols have been discussed and analyzed in terms for their energy efficiency and activity of routing in the network. Such as the major problems of these routing protocols are tried to remove or eliminate to come towards a more useful and better approach or routing in this report. The lack of centralized control of the Base station for TLLeach makes it harder for the energy efficient communication assurance. The vice Cluster Head failure for the V-LEACH can be disastrous for the network survival and the life expectancy. Thus, a huge amount of power wastage can occur. Delay observed in the multi hopping technique can be alarming for the network energy consumption rate of M-LEACH routing protocol. Next, a number of phase management in the network creates hustle to the processor capacity and power management of the $\mathrm{T}$ LEACH protocol. More adaptive and efficient duty cycle (sleep-active) for the R-LEACH protocol is needed to make it more energy efficient. Finally, the power backup of the solar aware LEACH-S protocol has been taken into considerations for further work in the enhanced protocol. The name of the proposed model is LEACH-S2 (Solar LEACH2).

\subsection{Feature of the Proposed Model}

The new LEACH protocol will have the following features in its routing activity among the clusters. They are:

- Solar energy as backup power source of the cluster: The energy from the sun is used to make the energy backup in the cluster nodes and it is both cost and energy effective approach. In case of power crisis, the power source can be transferred to the solar power gained from the daylight.

- CDMA or Code Division Multiple Access method in channel assignment for the nodes: The coded approach can be used for channel assignment for the nodes. Thus, it may reduce the probability of collision. As it may have less amount of collision and node failure for CDMA, it will save a good amount of energy in the network and it will be more energy efficient and less delay prone.

- Adaptive sleep-active duty cycle of the cluster nodes: The R-LEACH does not maintain an efficient and adaptive duty cycle of the cluster nodes. If this cycle is handled more efficiently and the adaptation of the mode of sleep / active is generated by the assistance of the sensors adaptation and power level analyzing capability rather than the time-based cycle, then it can be more energy efficient. As a number of nodes will be active as per the requirement but not as per the time interval.

- Constant performance measurement for a specific threshold level of energy for the nodes and the management for its efficient failure handling: It has been analyzed that the amount of energy level is not inspected efficiently by the Cluster Heads of the clusters. So, this proposal gives a concept of continuous energy level measurement to avoid the sudden failure of the $\mathrm{CH}$. If the failure of a $\mathrm{CH}$ is detected by reaching a certain energy threshold value in the clusters, the failure of the network can be reduced. It will save the energy of the $\mathrm{CH}$ and save it from dying also make the efficient handling of $\mathrm{CH}$ formation in the cluster. 
- Centralized control from the Base Station to the sensor nodes: There should be a centralized control from the BS to the sensors of the clusters. Thus, there may be a smaller number of failure of data passage and the protocol can observe the data formats and bandwidth levels of the sensor nodes while packet propagation from the cluster to the BS. IT can enhance the inter cluster and intra cluster data transmission efficiency and thus it can reduce the number of false routing which makes energy wastage.

\subsection{Flowchart of the proposed scheme}

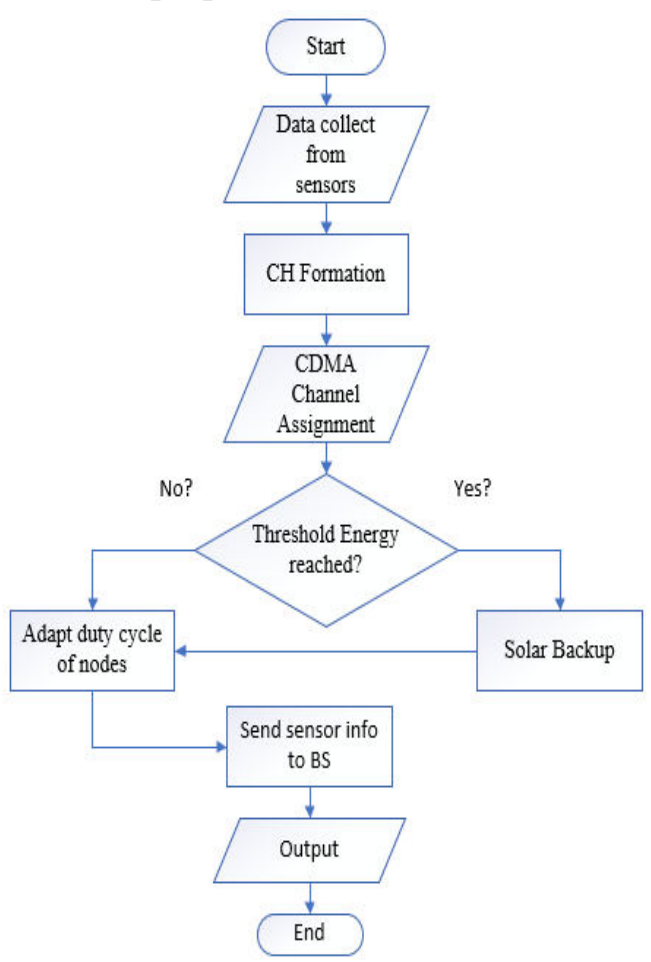

Fig.6. Flowchart of the proposed scheme

\subsection{Working Principle of the Proposed Model}

This scenario is based on one-unit packet propagation from the sensor node of a cluster to the Base station of the network. At first the data has been gathered from the sensor nodes of the cluster for a propagation to the Base station. Then the $\mathrm{CH}$ is formed according to the analysis of the energy unconsumed level reading of the clusters. Next, the Code Division Multiple Access method is used to assign the channel of the nodes information to be transmitted After that there is a check on the threshold level of the $\mathrm{CH}$ power that either it is reached or not. If the threshold is reached, then it has to be shifted to the solar power backup and then it has to construct and get the sleep or duty mode on for that particular node. If not, then after the threshold level of energy check for the Cluster Head it goes straight towards the adaption of duty cycle or mode of that particular sensor node. After the completion of these processes, the information of the sensor is sent to the Base station of the network. Finally, the output data is generated and used in the network for its successful and energy efficient activity through this LEACH-S2 routing protocol.

\subsection{Cost Analysis}

To Let's assume that the number of Sensors taken to use in the network is 25 . This is taken as a standard number of nodes in the environment of $400 \times 400 \mathrm{~m}^{2}$. The calculations will be made according to this number of sensors in the system.

\subsubsection{System Implementation Cost without Arduino}

- The average cost of a sensor is $1 \$$ or 93 BDT. So, the cost for using 25 sensors will be $25 \times 93=$ 2325 BDT.

- The cost of solar energy source is 180 BDT. If we use 20 backup solar source then, it will take 180 $\times 20=3600$ BDT .

- One energy level reading machine is of 1000 BDT. So, if 2 machines are used for the Cluster Head observation, then it will cost $2 \times 1000=$ 2000 BDT.

- $\quad$ Field Programming Gate (FPGA) is required for the internal system calculation and codded tasks to accomplish in the nodes. Each of them is 578 BDT / Bangladeshi currency. So, 25 number of FPGA needed for each sensor. Then the cost for codded gates will be $578 \times 25=14450$ BDT .

- Memory required for each of the sensors are minimal of $1 \mathrm{~GB}$ and it will cost 150 BDT each. so, the expense for the sensor memory is $=150 \times$ $25=3750 \mathrm{BDT}$.

Table 2: Required cost for Implementation (without Arduino)

\begin{tabular}{|c|c|c|c|}
\hline SL & Equipment & Quantity & Amount in BDT \\
\hline 1 & Sensor & 25 & $25 \times 93=2325$ \\
\hline 2 & Solar Source & 20 & $180 \times 20=3600$ \\
\hline 3 & $\begin{array}{c}\text { Energy Reading } \\
\text { Machine }\end{array}$ & 2 & $2 \times 1000=2000$ \\
\hline 4 & FPGA & 25 & $578 \times 25=14450$ \\
\hline 5 & Memory & 25 & $150 \times 25=3750$ \\
\hline \multicolumn{2}{|c|}{ Total } & \multicolumn{3}{|c}{26125 BDT } \\
\hline
\end{tabular}

\subsubsection{System Implementation Cost with Arduino}

If Arduino NRF24L01 model is used for system integration of 25 nodes, then no external memory, no FPGA and no energy level detection meter is required. For this, the total cost will be only for the nodes and one Arduino model.

- $\quad$ Cost for the nodes $=25 \times 93=2325$ BDT

- Cost for the Arduino model=85 BDT

- Cost for solar panels $=20 \times 180=3600$ BDT

- Cost for wires=250 BDT 
Table 3: Required cost for Implementation (with Arduino)

\begin{tabular}{|c|c|c|c|}
\hline SL & Equipment & Quantity & Amount in BDT \\
\hline 1 & Sensor & 25 & $25 \times 93=2325$ \\
\hline 2 & Solar Source & 20 & $180 \times 20=3600$ \\
\hline 3 & Wires & 100 & $100 \times 2.5=250$ \\
\hline 4 & Arduino & 1 & $1 \times 85=85$ \\
\hline \multicolumn{2}{|c|}{ Total } & \multicolumn{3}{c}{6260 BDT } \\
\hline
\end{tabular}

This is only the cost for implementation of the system and the calculations supports the equipment requirement to make the routing work in the environment. The cost of constructing the wireless network is excluded.

\subsection{Discussion}

Since, the discussed $6 \mathrm{LEACH}$ protocols are themselves energy efficient, yet these protocols have been found with some small drawbacks. It has been shown in table 1 . The proposed scheme has shown that the problems found in the mentioned LEACH protocols have been solved by changing the routing protocols slightly from each of those protocols. Just like, the backup solar source would accomplish the need of extra power source to reduce the probabilities of network failure. The adaptive duty cycle can perform better than the time constrained duty cycle by saving energy. Code Division Multiple Access (CDMA) is less collision prone, and it may have less collisions in the channel which results in lower energy consumption. The processing overhead in the BS may put the sensor nodes into less computational activities which leads to lesser energy dissipation than before. Therefore, it can be concluded and summarized that the proposed S2-LEACH protocol can be more energy efficient than the other $\mathrm{LEACH}$ routing protocols discussed.

\section{CONCLUSION}

LEACH-S2 protocol has been proposed in this report. This protocol is discussed along with the comparison with the V-LEACH, M-LEACH, R-LEACH, TL-LEACH, TLEACH and S-LEACH protocols of routing by considering the energy consumption-oriented issues found in them. In the end the systematic description of the proposed routing activity is discussed with proper justification and visualization of the single packet routing by a flowchart is produced to ease the understanding of the concept.

\section{FUTURE WORK}

In this paper, we have only given the proposal of a new LEACH protocol. We assume that it will be give better performance than the others. In future, we may make the stimulatory analysis the proposed protocol. It can be extended for a big network, and we will also do this to prove that the proposed protocol is the best one among the mentioned ones. The performance of a cluster network can also be enhanced with a secure key management mechanism over the cloud platform. The Vehicle oriented network platform can consider an asymmetric key based authentication service through encryption [13]. The security of the service may enhance the QoS of the specific cluster network. If the routing process of these clusters is linked with the concept of key integrity and public key cryptography, the service may get more reliable, upgraded, and efficient in case of unwanted access to the system traffic.

\section{REFERENCES}

[1] G. Arumugam and T. Ponnuchamy, "EE-LEACH: development of energy-efficient LEACH Protocol for data gathering in WSN", EURASIP Journal on Wireless Communications and Networking, vol. 2015, no. 1, 2015. Available: 10.1186/s13638-015-0306-5.

[2] C. Nakas, D. Kandris and G. Visvardis, "Energy Efficient Routing in Wireless Sensor Networks: A Comprehensive Survey", Algorithms, vol. 13, no. 3, p. 72, 2020. Available: 10.3390/a13030072.

[3] Y. Zhu, W. Wu, J. Pan and Y. Tang, "An energyefficient data gathering algorithm to prolong lifetime of wireless sensor networks", Computer Communications, vol. 33, no. 5, pp. 639-647, 2010. Available: 10.1016/j.comcom.2009.11.008.

[4] H. Brahmia and C. Tolba, "Nakagami Fading Impact on the Performances of VANET Routing Protocols in a Realistic Urban", International Journal of Advanced Networking and Applications, vol. 11, no. 04, pp. 4330-4335, 2020. Available: 10.35444/ijana.2020.11042.

[5] G. Pandey and P. Mishra, "A Short Review Of Some Of The Unequal Clustering Algorithms In Wireless Sensor Networks", International Journal of Advanced Networking and Applications, vol. 12, no. 05, pp. 4677-4690, 2021. Available: 10.35444/ijana.2021.12503.

[6] V. Loscr, G. Morabito, and S. Marano, "A TwoLevels Hierarchy for Low-Energy Adaptive Clustering Hierarchy (TL-LEACH)", IEEE vehicular technology conference, vol. 62, no. 3, Sep. 2005.

[7] D. Prabha and V. Kumar Arora, "A Survey on LEACH and its Descendant Protocols in Wireless Sensor Network," International Conference on Communication, Computing \& Systems, pp. 162-167.

[8] M. A. Al SIBAHEE, S. LU, M. Z. MASOUD, Z. Alaa HUSSIEN, M. Abdulridha HUSSAIN, and Z. Ameen ABDULJABBAR, "LEACH-T: LEACH Clustering Protocol Based on Three Layers", 2016 International Conference on Network and Information Systems for Computers, pp. 36-40, Apr. 2016.

[9] T. Sharma, H. singh and A. sharma, "Compare and Analyses of Optimized R-Leach With Leach Algorithm In WSN", International Journal on Soft Computing, vol. 6, no. 4, pp. 01-09, 2015. Available: 10.5121/ijsc.2015.6401

[10] Yassein, "Improvement on LEACH Protocol of Wireless Sensor Network (VLEACH)", International 
Journal of Digital Content: Technology and its Applications, vol. 3, no. 2, 2009. Available: 10.4156/jdcta.vol3.issue2.yassein.

[11] G. Devika and A. G. Karegowda, "A pragmatic study of $\mathrm{LEACH}$ and its descendant routing protocols in WSN", International Journal of Computational Intelligence and Informatics, 2015.

[12] J. Gnanambigai, D. N. Rengarajan, and K. Anbukkarasi, "Leach and Its Descendant Protocols: A Survey", International Journal of Communication and Computer Technologies, vol. 1(3), no. 2, pp. 15-21, Sep. 2012.

[13] N. Hegde and S. S. Manvi, "Secure Group Key Management Scheme For Dynamic Vehicular Cloud Computing", International Journal of Advanced Networking and Applications, vol. 13, no. 01, pp. 4821-4826, 2021. Available: 10.35444/ijana.2021.13103.

\section{Biographies and Photographs}

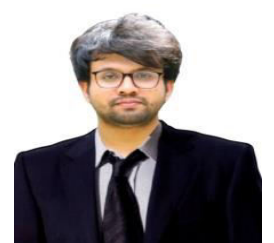

Md. Faruk Abdullah Al Sohan received his B.Sc. degree in Computer Science and Engineering from American International University-Bangladesh (AIUB), in 2020 and currently pursuing the MScs degree in Computer Science at the same university. His research interest includes, and passion are mostly based on Network Security, Neural Network, Image Processing, Internet of Things (IoT), Block Chain Technology, Artificial Intelligence, Machine Learning and Database Design.

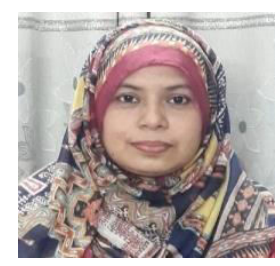

Dr. Afroza Nahar received her $\mathrm{PhD}$ degree from University of Malaya, Malaysia. Prior to that she earned a M. Sc in Computer Science from Asian Institute of Technology (AIT), Thailand and another in Applied Mathematics from University of

Dhaka, Bangladesh

Currently, she is working as an Associate Professor in the Department of Computer Science at American International University-Bangladesh (AIUB). Dr. Nahar published several research works in ISI-indexed high impact factor journals and presented many papers in prestigious international conferences. Her major research interests include Computational Modeling, Renewable Energy System, Distributed Computing, Wireless Sensor Network etc.

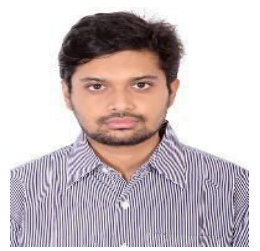

MD Sajid Bin- Faisal is currently working as a lecturer of Computer Science (CS) department at American International University-Bangladesh. $\mathrm{He}$ passed his BSc in Computer Science and Engineering (CSE) and Master of Science in Computer Science with Computer
Network and Architecture as major. He has his research contributions over network security domain and cryptography for data security. $\mathrm{He}$ has worked over Internet of Things in his academic career. He also has a great interest over both symmetric and asymmetric encryption systems. The basic graph theory, Computer Science mathematics, Algorithms and Discrete Mathematics are also his area of enthusiasm. 